\title{
Effect of Different Curry Flavor Concentrations on the Fermentation Process and Lactic Acid Bacteria of Layang Scad (Decapterus macrosoma)
}

\author{
Roshita Ibrahim $^{1, *}$, Kunasundari Balakrishnan ${ }^{1}$, and Norsaliha Musa ${ }^{1}$ \\ ${ }^{1}$ Department of Chemical Engineering Technology, Faculty of Engineering Technology, UniCITI \\ Alam Campus, Universiti Malaysia Perlis (UniMAP), 02100 Sungai Chuchuh, Padang Besar, Perlis, \\ Malaysia
}

\begin{abstract}
For various socio-economic and technical factors, fermentation process is among the commonly used method for fish preservation in South-Eastern Asia. However, the fermented fish were not well accepted by some people due to its unpleasant odour and unique taste. In this study, layang scad (Decapretus macrosoma) has been used to study the effect of different curry flavor concentrations on the fermentation process and microflora of lactic acid bacteria. This study was carried out to determine the physical characteristics, microflora of lactic acid bacteria and sensory acceptability of the product. The fish were fermented for 10 days with different concentrations of curry flavor which were at $5 \%, 7.5 \%, 10 \%$ and control, no addition of curry flavor. The fermented fish were analyzed in terms of $\mathrm{pH}$, firmness, lactic acid concentration and sensory evaluation. Over the fermentation period, $\mathrm{pH}$ and firmness values were decreased. Meanwhile, the concentration of lactic acid and colony-forming unit (CFU) of lactic acid bacteria were increased. The effect of fermentation by using different concentrations of curry flavor was observed and no significant different was found on CFU of lactic acid on MRS and M17 agar. Sensory evaluation showed that fermented fish with $10 \%$ concentration of curry flavor is the most acceptable by the sensory panelists as it has the highest acceptability score compared to other concentrations. It can be concluded that addition of $10 \%$ curry flavor in the formulation of fermented fish is the best in terms of physical characteristic, microbial quality and sensory acceptability.
\end{abstract}

\section{Introduction}

The cuisines of East Asia are usually based on the combination of rice, vegetables and proteins obtained mainly from aquatic living, fish [1]. Fish such as layang scad, (Decapterus macrosoma) contains a lot of protein that are required by human to maintain a healthy body. Fish is an important source of protein where it is rich in amino acids such as cystine, lysine, methionine, tryptophan and threonine [2]. Other than that, fish also contain microelements

\footnotetext{
*Corresponding author: roshita@unimap.edu.my
} 
and macroelements like phosphorus, calcium, iodine and fluorine. Ismail (2005)[3] reported that fish also provide fats that act as energy sources, fat-soluble vitamins, and unsaturated fatty acids which have a hypo-cholesterolemic effect or anti-arteriosclerosis.

Fish, the most important source of proteins are easily spoiled after being caught, hence, need to be preserved. This is because the immune system of fish collapses after the fish died and bacteria are allowed to proliferate freely in the fish. Preservation of fish by applying the principles of engineering, chemistry and other branches of science is the method to increase the shelf life of fish products so that they can be stored longer because certain type of fish usually available only during certain seasons of the year and fresh fish spoils quickly [4]. Therefore, several methods of preservation of fish had been introduced such as salting, drying, cooling, freezing, canning and fermentation [4].

Preservation of food by fermentation does not only extend the shelf-life, it also improves the functional and nutritional properties of the food. Cleavage of proteins in food by microbial or indigenous proteases produced the bioactive peptides, substantially increases biological properties of the products [5]. Rajapakse et al. (2003)[6] stated that fermented food products are good source of amino acids and peptides. Fermentation process requires microorganisms with the enzymatic capacity like bacteria and yeast, specifically bacteria for lactic acid fermentation and yeast for ethanol fermentation [7].

Lactic acid bacteria (LAB) is the most frequently used microorganism in fermentation process of fish. They are important due to their metabolic capabilities and other physiological properties such as probiotic and substrate utilization properties. Silva et al. (2002)[8] reported that lactic acid bacteria have long been accepted as Generally Recognized as Safe (GRAS) to be consumed by Food and Drug Administration (FDA). A variety of LABs have been recognized from various fermentation products along with their function during or after fermentation process have increasingly been clarified [9].

\section{Material and methods}

This section details out the sample sources and preparations, the ingredients and procedures used in producing fermented fish and the analyses carried out which were physico-chemical analyses, the lactic acid micro-flora during fermentation and sensory evaluation of the fermented fish.

\subsection{Sample sources and preparations}

The samples for this project were layang scads that had commercial value for market which were obtained from a wet market in Kangar, Perlis. The length of the fish was about $150 \mathrm{~mm}$ with width of $30 \mathrm{~mm}$ and depth of $15 \mathrm{~mm}$. The fish were gutted and washed from dirt and blood using ice water. The fish were then toss-dried to remove the excess water and weighed using weighing scale.

\subsection{Fermentation ingredients}

Other fermentation ingredients that were used in this study were fine and coarse salt, palm sugar, roasted rice and curry flavor.

\subsection{Production of fermented layang scad}

Fresh layang scads were gutted and the intestines and fins were removed. The fish were thoroughly washed and drained then salted using fine and coarse table salt at $15 \%(\mathrm{w} / \mathrm{w})$ and 
kept in airtight container for 24 hours. The salted fish were then drained from the brine solution and coated with mixture of roasted rice, palm sugar and flavors at different concentrations. The fish were then kept in airtight containers at about $25^{\circ} \mathrm{C}$ according to different flavors concentration for fermentation process. The analysis of the physico-chemical properties of the fermented of the fermented fish were then carried out at 2 days intervals until day $10(0,2,4,6,8$ and 10 days). The degree of the fermentation process was determined mainly by the measurement of $\mathrm{pH}$. Other physico-chemical properties measured were such as texture and lactic acid concentration. The sensory evaluation was also done after 6 days of fermentation to evaluate the acceptability of the fermented layang scad with different curry flavor concentrations.

\subsection{Physico-chemical analyses:}

The physico-chemical analyses involved the determination of the changes in $\mathrm{pH}$ and texture (firmness) during the fermentation process.

\subsection{1 $\mathrm{pH}$ determination}

The $\mathrm{pH}$ of the fish was measured on day 0 until day 10 , with every 2 days intervals. This study was using $\mathrm{pH}$ meter to determine the $\mathrm{pH}$ data and the relationship between $\mathrm{pH}$ and formation of the lactic acid during fish fermentation. The $\mathrm{pH}$ meter was calibrated with buffer $\mathrm{pH} 7$ and $\mathrm{pH} 4$ for every different flavor concentrations.

\subsubsection{Texture (Firmness) determination}

The fish's nature was determined on day 0 until day 10, with every 2 days intervals. The firmness of the fish flesh was determined using Brookfield CT3 Texture Analyzer using TA10 stainless steel cylinder probe. The testing parameters were as follows:

Test mode: Compression

Pre-test speed: $1.0 \mathrm{~mm} / \mathrm{sec}$

Test speed: $0.5 \mathrm{~mm} / \mathrm{sec}$

Distance: $5.0 \mathrm{~mm}$

\subsection{Sample preparation for lactic acid bacteria studies}

An amount of $10 \mathrm{~g}$ of fermented fish flesh was weighed and aseptically put into sterile food blender and mixed with $90 \mathrm{ml}$ of sterile distilled water. The flesh was blended until homogenized for about 2 minutes in laminar flow and diluted up to $10^{-4}$ concentration. An amount of $0.1 \mathrm{ml}$ of the sample was plated onto agar plate by using micropipette and spread on the agar plate. The same aqueous sample also was used for lactic acid determination.

\subsubsection{Determination concentration of lactic acid}

The samples were analyzed by dipping the lactic acid strip into the sample and inserted into the reflectoquant. The reading was taken and recorded. 


\subsubsection{Determination of lactic acid bacteria using De Man, Rogosa and Sharpe (MRS) agar}

MRS media was prepared by dissolving $62 \mathrm{~g}$ of MRS agar in $1000 \mathrm{ml}$ of distilled water. It was then boiled to dissolve the medium completely. The dissolved media were then sterilized by autoclaving at $121^{\circ} \mathrm{C}$ for 15 minutes. An amount of $0.1 \mathrm{ml}$ of homogenized sample was plated onto De Man Rogosa and Sharpe (MRS) agar for isolation of lactobacillus species. Lactobacilli MRS Agar was developed by researchers De Man, Rogosa and Sharpe as an alternative non-selective media for the cultivation of fastidious lactobacilli. All the plates were then incubated for up to 3 days at $35^{\circ} \mathrm{C}$ in an anaerobic jar. The $\mathrm{CFU}$ of lactic acid on MRS media was counted and recorded.

\subsubsection{Determination of lactic acid bacteria using M17 agar}

M17 media was prepared by dissolving $50 \mathrm{~g}$ agar in $950 \mathrm{ml}$ of distilled water and bring slowly to a boil. The mixture was sterilized by autoclaving at $121^{\circ} \mathrm{C}$ for 15 minutes. It was then cooled and added with $50 \mathrm{ml}$ of sterile $10 \%$ lactose solution. The solution was then mixed thoroughly and dispended into petri dish. M17 agar was used for cultivation of the fastidious species Streptococcus cremoris, Streptococcus lactis and Streptococcus diacetilactis. An amount of $0.1 \mathrm{ml}$ of homogenized sample was plated onto M17 agar before incubated for up to 3 days at $35^{\circ} \mathrm{C}$ in an anaerobic jar. The CFU of lactic acid on M17 media was counted and recorded.

\subsection{Sensory evaluation}

The fermented fish were served to 30 respondents who were randomly selected among students and staffs of Universiti Malaysia Perlis. 7 point hedonic scales were used where score 1 indicating the most unacceptable, score 4 neither acceptable nor unacceptable and score 7 indicating the most acceptable. The respondents were presented with four fermented fish of different curry flavour concentrations and their evaluations were based on the attributes of colour, texture, aroma, taste and overall acceptability. The fermented fish were also served with rice, water and sensory evaluation form which were provided to each respondent to assist the process.

\subsection{Data analysis}

All the data obtained from the physico-chemical analyses were analysed by using one-way Analysis of Variance (ANOVA) and significant differences among the treatments were determined using Tukey Multiple Comparison Test at $\mathrm{p}<0.05$ from SAS software.

\section{Results and discussions}

This section reported on the results obtained which highlighted the changes in the physico-chemical properties, lactic acid bacteria studies and the sensory acceptability of fermented laying scads.

\subsection{Changes in physico-chemical properties}

Changes in $\mathrm{pH}$ of fermented layang scad with different curry flavor concentrations during fermentation period are shown in Fig. 1. The initial $\mathrm{pH}$ of all samples at day 0 was the same 
at $\mathrm{pH}$ 6.03. Generally the $\mathrm{pH}$ of the fermented fish with or without the addition of curry flavor showed a decreasing trend as the fermentation progress until day 8 . This may be due to the release of free amino acids from proteins and large polypeptides. After day 8 , the $\mathrm{pH}$ of all the samples started to increase. This might probably due to the beginning of putrefaction or spoilage process.

Among all the treatments, fermented fish with addition of curry flavour regardless its concentrations showed more drastic decrease in $\mathrm{pH}$ compared to control. This might probably be due to more production of lactic acid which results in lower $\mathrm{pH}$ values. However, among three concentrations of curry flavour the decrease in $\mathrm{pH}$ was observed to be much faster in the fermented fish with lower concentration $(5 \%)$ compared to $10 \%$ concentration. The drop in $\mathrm{pH}$ value on the first few days of fermentation was also observed in the study of El Hag et al. (2012)[10].

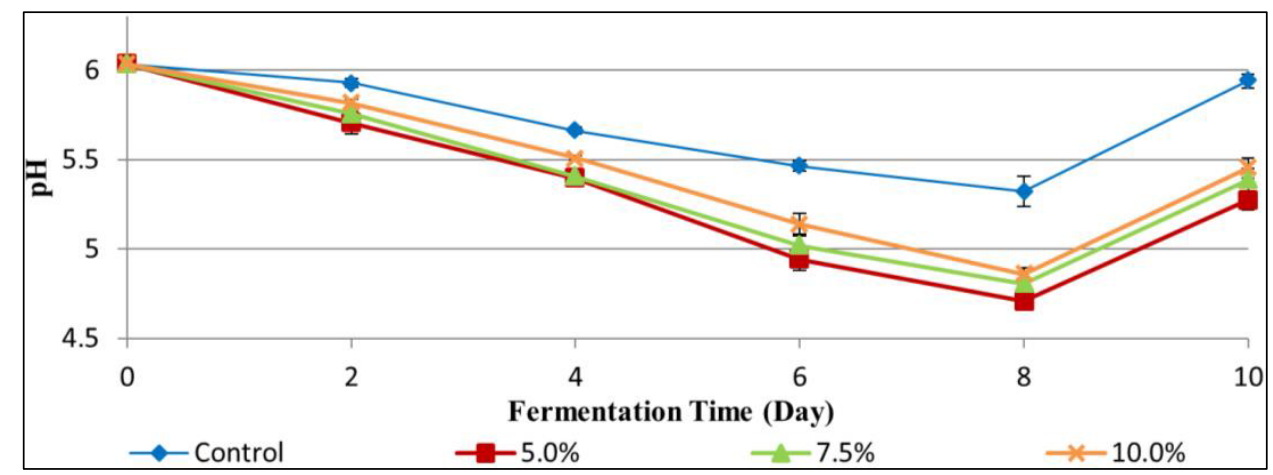

Fig. 1. $\mathrm{pH}$ of fermented layang scad with different concentrations of curry flavor during fermentation process. Vertical bars represent standard errors.

The changes in texture (firmness) of fermented layang scad with different curry flavor concentrations during fermentation are shown in Fig. 2. Higher addition of curry flavor resulted in decreased in the firmness of the fermented fish. Addition of curry flavor had a great influence on the textural properties of fermented fish. During fermentation, the samples with $5 \%$ curry had significantly $(\mathrm{p}<0.05)$ the most firm texture, whilst no significant difference in the samples between $7.5 \%$ and $10 \%$ concentrations. The development of firmness is related to $\mathrm{pH}$ reduction and moisture removal [11]. It was also reported that texture formation of fermented fish was closely associated to the rapid decline in $\mathrm{pH}$, which induced conformational changes of gelation. Higher acidity in the fermented fish with the addition of curry flavor resulted in superior organoleptic properties. 


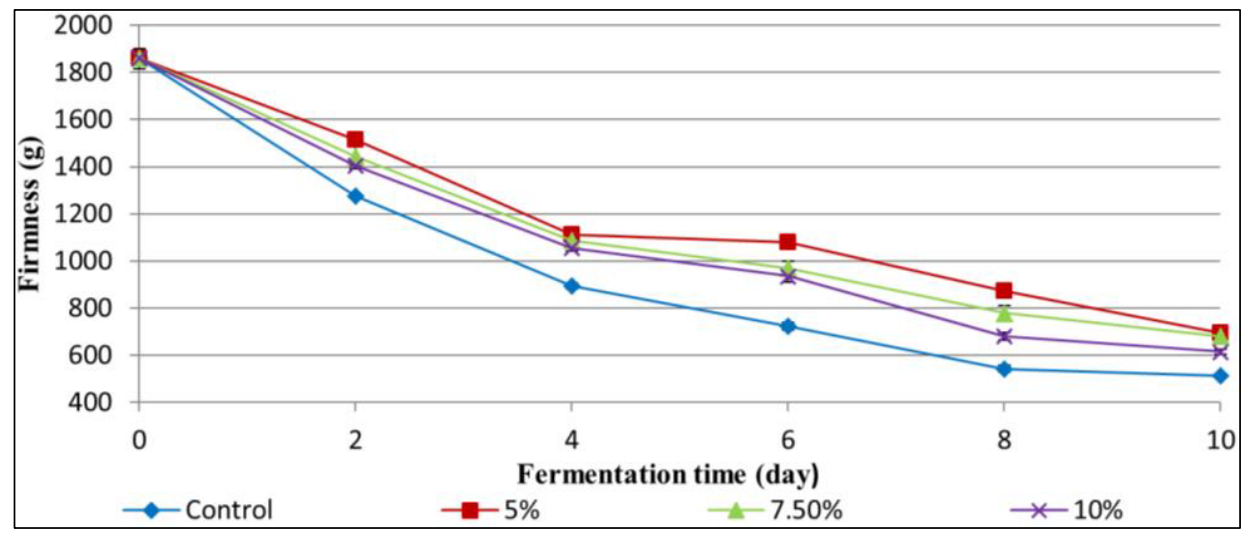

Fig. 2. The texture (firmness) of fermented layang scad with addition of different concentrations of curry flavor during fermentation process. Vertical bars represent standard errors.

The concentration of lactic acid on fermented layang scad with different curry flavor concentrations during fermentation are shown in Fig. 3.

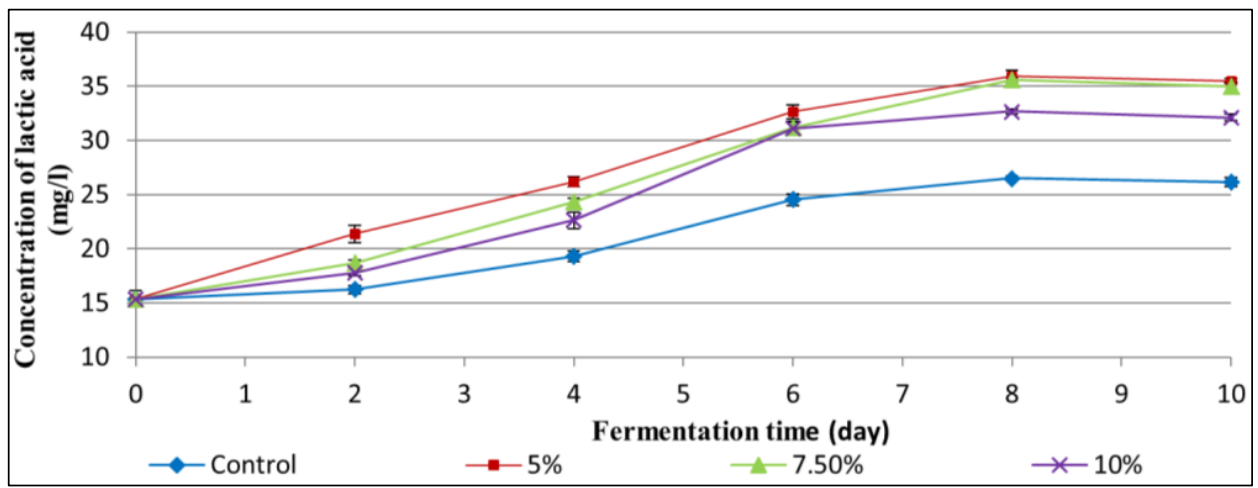

Fig. 3. Lactic acid concentration determined on fermented layang scad with addition of different curry flavor concentrations during fermentation process. Vertical bars represent standard errors.

The general trend of the concentration of lactic acid in fermented layang scad for all treatment was increasing during fermentation from day 0 until day 8 . The concentration of lactic acid started to plateu off after day 8. Control fish showed the lowest concentration of lactic acid as compared to the curry flavoured fermented fish.

Based on Fig. 3, on day 0 , there was no significant different in concentration of lactic acid of the fermented fish for all treatment. There were significant differences $(p<0.05)$ among different curry concentration of lactic acid concentration on day 2 until day 10 . The trends were the same for all treatments during the fermentation period where the $5 \%$ curry concentration showed the highest significant value as compared to other treatments.

The increasing of concentration of lactic acid were due to the decreasing in $\mathrm{pH}$ of fermented layang scad during fermentation progress. As the $\mathrm{pH}$ decreases the concentration will eventually increases as lactic acid bacteria prefer relatively acidic conditions, where the growth of spoilage and pathogenic bacteria were inhibited. 


\subsection{The microflora of lactic acid bacteria}

The determination of microflora of lactic acid bacteria on fermented layang scad with different curry flavour concentrations by using MRS agar are shown in Fig. 4.

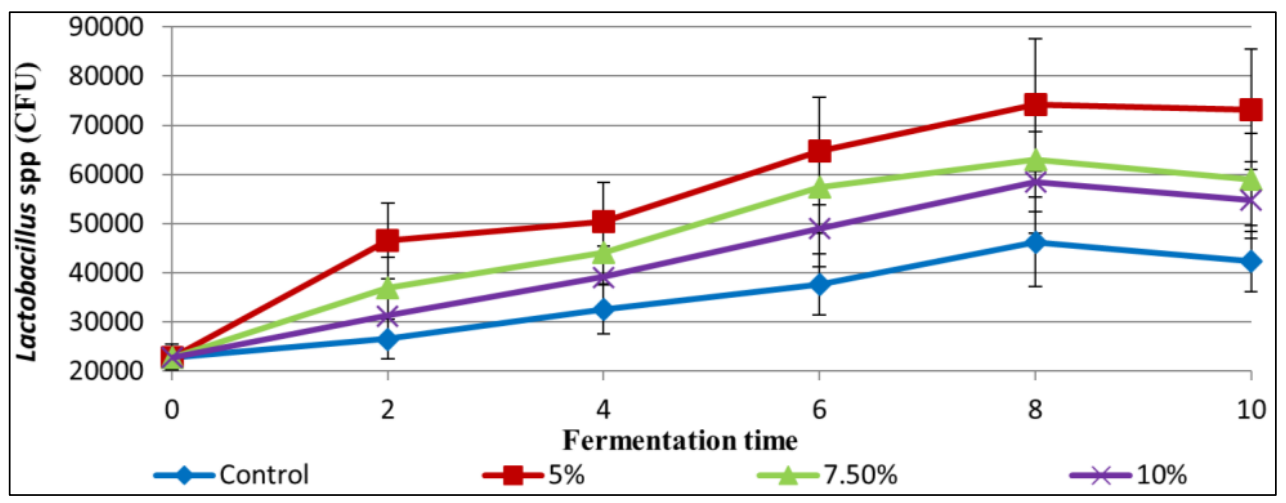

Fig. 4. CFU of lactic acid bacteria on fermented layang scad with addition of different curry flavour concentrations during fermentation process. Vertical bars represent the standard errors.

Generally the CFU of lactic acid bacteria of the fermented fish with or without addition of curry flavour showed an increasing trend as the fermentation progress. The highest CFU of Lactobacillus spp.was observed on day 8 , for $5 \%$ curry flavour with value of 74167 . After day 8 , the CFU for all treatment started to decline. The increasing and decreasing CFU were due to the changes in $\mathrm{pH}$ of fermented layang scad during fermentation progress. As the $\mathrm{pH}$ decreases the CFU will eventually increases. Although there were high difference in number of CFU, there was no significant different ( $p>0.05)$ among all the treatments in terms of the $\mathrm{CFU}$ of lactobacillus in fermented layang scad.

The determination of microflora of lactic acid bacteria on fermented layang scad with different curry flavour concentrations by using M17 media during fermentation are shown in Figure 5.

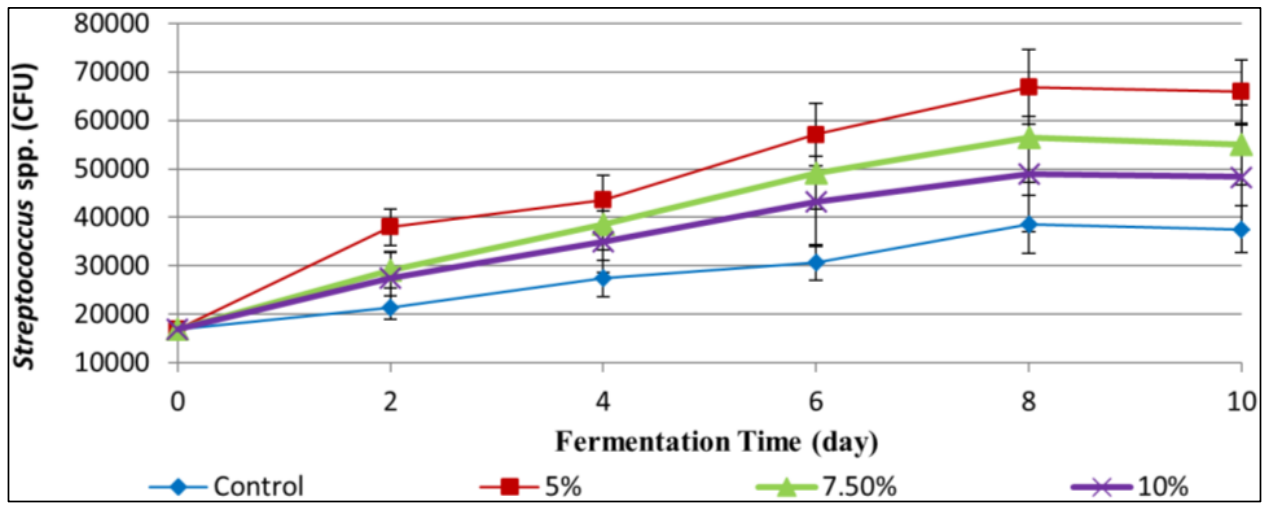

Fig. 5. CFU of lactic acid bacteria (Streptococcus spp.) on fermented layang scad with addition of different curry flavour concentrations during fermentation process. Vertical bars represent the standard errors.

Generally the CFU of streptococcus of the fermented layang scad with or without addition of curry flavour showed an increasing trend as the fermentation progress. The highest CFU was observed on day 8 , for $5 \%$ curry flavour with value of 66990 . After day 8 , 
the CFU for all treatment had a slight decline. Although there were high difference in number of CFU, there was no significant different $(\mathrm{p}>0.05)$ among all the treatments in terms of the CFU. The CFU for lactic acid bacteria of M17 agar for all treatment during the fermentation period were always lower than that of MRS agar. This showed that the fermented layang scad contained more Lactobacillus spp. than Streptococcus spp.

\subsection{Sensory Acceptability}

The sensory evaluation test of fermented layang scad with different concentrations of curry flavour was carried out by 30 panelist and the results of their acceptability are shown in Fig. 6.

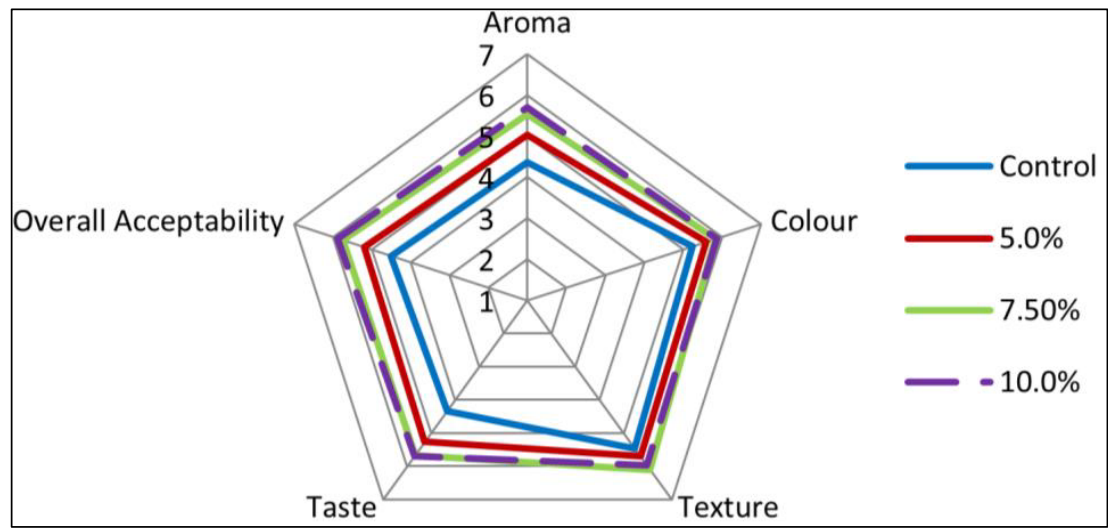

Fig. 6. Sensory acceptability of fermented layang scad with addition of different curry flavour concentrations.

\section{Summary}

In conclusion, the results of present study have indicated that the addition of curry flavor during fermentation of layang scad can give added value to the products in term of its texture, colour, aroma and taste. Over fermentation period, $\mathrm{pH}$ and firmness were decreased. Meanwhile, the lactic acid concentration and its CFU were increased. Since there was no chemical used in this process, this process would provide a safe product and also inhibit the growth of pathogenic microorganisms. Sensory evaluation showed that samples prepared using $10 \%$ curry concentrations are the most acceptable by the sensory panelists.

The addition of different concentrations of curry flavor during fish fermentation could also improve the sensory attributes of end product, and it can be concluded that the higher the concentration of curry used, the better the acceptance. The obtained results led us to conclude that the use of curry flavor could improve the preservation and fermentation of fish.

The authors would like to express their appreciations to Universiti Malaysia Perlis (UniMAP) for facilitating this project.

\section{References}

1. Ruddle, Kenneth, Naomichi Ishige, On the origins, diffusion and cultural context of fermented fish products in Southeast Asia (lobalization, Food and Social Identities in the Asia Pacific Region. Sophia University Institute of Comparative Culture, Tokyo, 2010)

2. Usydus, Zygmunt, Joanna Szlinder-Richert, Maria Adamczyk, Food Chem., 112, 139 (2009) 
3. Ismail, M. Hassan, Front Biosci., 10, 1079 (2005)

4. Van Berkel, B.M.B. Boogaard, C. Heijnen, Preservation of fish and meat, (Technical Centre for Agricultural and Rural Co-operation, Wageningen (Países Bajos) (2004)

5. Steinkraus, H. Keit, Compr. Rev. Food Sci. F., 1, 23 (2002)

6. N. Rajapakse, E. Mendis, W.K. Jung, J.Y. Je, S.K. Kim, Food Res. Int., 38, 175 (2005)

7. Chilton, N. Stephanie, Jeremy P. Burton, Gregor Reid, Nutrients, 7, 390 (2015)

8. J. Silva, A.S. Carvalho, P. Teixeira, P.A. Gibbs, Lett. Appl. Microbiol., 34, 77 (2002)

9. Liu, Shan na, Ye Han, Zhi jiang Zhou, Food Res. Int., 44, 643 (2011)

10. G.A. El Hag, B.Y. Abu Gideiri, M.E. Ali, I.M. Abu Zied, New York Science Journal, 5, 32 (2012)

11. Riebroy, Siriporn, Soottawat Benjakul, Wonnop Visessanguan, LWT-Food Sci. Technol., 41, 569 (2008) 